\title{
Matriz de Contabilidad Social: Reflexiones PARA EL ANÁLISIS ECONÓMICO DE MÉXICO
}

\author{
Andrés Blancas ${ }^{\mathrm{a}}$ y Rodrigo Aliphat ${ }^{\mathrm{b}}$
}

Fecha de recepción: 24 de septiembre de 2020. Fecha de aceptación: 24 de febrero de 2021.

$$
\text { https://doi.org/10.22201/iiec.20078951e.2021.205.69711 }
$$

Resumen. El texto muestra la construcción y utilidad de una Matriz de Contabilidad Social (мCs) para México 2013; presenta la metodología para su elaboración, características y cualidades como herramienta contable para la evaluación de la política económica vinculada al estudio del crecimiento y desarrollo económico. La MCs incluye 21 sectores económicos, cuatro tipos de industrias de bienes de importación y cuatro sectores institucionales subdivididos en hogares de ingreso bajo, medio y alto; así como sociedades financieras y no financieras públicas y privadas, gobierno y resto del mundo. Con una MCs se puede observar a detalle la situación de la estructura productiva y de los sectores institucionales de la economía mexicana a través del análisis interinstitucional.

Palabras clave: Matriz de Contabilidad Social; desarrollo económico; distribución del ingreso-gasto de hogares; industrialización; política económica.

Clasificación JEL: E16; O11; O15; E01; E02.

\section{Social Accounting Matrix: AN ECONOMIC ANALYSIS OF MEXICO}

\begin{abstract}
This article illustrates the construction and usefulness of a Social Accounting Matrix (SAM) for Mexico, 2013, presenting the methodology used for its elaboration, as well as its characteristics and qualities as an accounting tool for the evaluation of economic policy linked to the study of economic growth and development. The SAM includes 21 economic sectors, four types of import goods industries, and four institutional sectors subdivided into low-, middle-, and high-income households; financial and non-financial corporations (public and private), government, and the rest of the world. Via inter-institutional analysis, sams allow for the detailed observation of the productive structure and the institutional sectors of the Mexican economy.
\end{abstract}

Key Words: Social Accounting Matrix; economic development; household incomeexpenditure distribution; industrialization; economic policy.

\footnotetext{
${ }^{a}$ Universidad Nacional Autónoma de México (UNAM)-Instituto de Investigaciones Económicas (IIEc), México; ${ }^{b}$ Doctorante del posgrado en Economía de la unam-IIEC, México. Correos electrónicos: neria@unam.mxy raliphat@hotmail.com, respectivamente.
} 


\section{INTRODUCCIÓN}

La Matriz de Contabilidad Social (MCS) constituye una herramienta contable útil y poderosa para el análisis económico, sobre todo, para la evaluación económica vinculada al crecimiento y desarrollo económico. Tomando como referencia las tablas de Quesnay (1894), Leontief (1941) desarrolló la idea del flujo circular de la economía en lo que denominó Matriz de Insumo-Producto (MIP) para analizar las transacciones económicas entre los sectores productivos de la economía. Esta matriz le permitió tener una imagen detallada de las relaciones económicas de los sectores productivos. Posteriormente, Stone (1956) ${ }^{2}$ incorpora a la MIP los sectores institucionales, que resultó en la conocida MCs. A diferencia del análisis con MIP, el uso de las MCs permite analizar específicamente la relación del sector productivo con hogares, gobierno, sociedades y resto del mundo.

El objetivo principal de este texto es mostrar la utilidad de una MCs para el análisis contable interinstitucional y su relación con el desarrollo de la economía mexicana. A partir de un análisis de las relaciones interinstitucionales de los agentes económicos se traza un puente entre el análisis de la producción y distribución del ingreso, incluyendo las transacciones realizadas desde el gobierno, sociedades y resto del mundo hacia los hogares. Aporta además, un enfoque metodológico para el análisis de la relación entre la MCS y el desarrollo económico, y combina la información disponible de los sectores productivos y del sistema de cuenta institucionales. La MCs-México 2013 que se presenta incluye 21 sectores económicos, cuatro tipos de industrias de bienes de importaciones y cuatro sectores institucionales subdivididos en hogares por tipo de ingreso (bajo, medio y alto), sociedades financieras y no financieras públicas y privadas, gobierno y resto del mundo. Hasta el momento no se ha publicado una MCs con el nivel de desagregación mencionado. Para elaborar la MCs se empleó la información de la MIP 2013 y del sistema de cuentas institucionales, así como información de datos de la Encuesta Nacional Ingreso Gasto de los Hogares (ENIGH) del INEgi y de la balanza de pagos publicada por el Banco de México.

1 En 1973 Leontief obtuvo el Premio Nobel de Economía por sus aportaciones teóricas y empíricas sobre el Modelo de Insumo-Producto.

2 En 1984 Stone obtuvo el Premio Nobel de Economía por sus aportaciones al sistema de cuentas nacionales, incluyendo sus planteamientos sobre la MCs y que fueron retomados por la Organización de las Naciones Unidas (ONU). 
El documento se organiza de la siguiente manera: después de la introducción se presentan cuatro secciones. En la segunda sección se hace un breve recorrido por la definición y características de una MCs. La tercera sección presenta la metodología seguida para elaborar la MCs-México 2013, finalizando con la presentación de la matriz. En la cuarta sección se realiza un análisis descriptivo de la economía mexicana tomando como referencia los resultados de la matriz que sirven como base para posteriores análisis interinstitucionales, $y$, finalmente, se presentan las conclusiones.

La MCs-México 2013 constituye, por su nivel de desagregación e información presentada, una herramienta metodológica útil para el análisis de desarrollo económico en México. La matriz propuesta permitirá elaborar y evaluar políticas públicas mejor focalizadas en atender no sólo el crecimiento económico, sino también, las formas de distribución de ese crecimiento entre los sectores institucionales de la economía.

\section{DEFINICIÓN Y CARACTERÍSTICAS DE LA MCS-MÉXICO 2013}

La elaboración y formato de presentación de la MCs considera la metodología del Sistema de Cuentas Nacionales (onU, 1993 y 2016) y tiene una estructura similar a las MCs publicadas por la Organización Internacional del Trabajo (Organización Internacional del Trabajo [отт], 2019) y el Instituto Internacional de Investigaciones sobre Políticas Alimentarias (Breisinger et al., 2009). La MCs es una representación contable de las transacciones realizadas entre los sectores productivos e institucionales de la economía. Siguiendo el método de partida doble se obtiene una matriz cuadrada en la que cada registro contable tiene una fila (ingresos) y columna (gastos); el valor total de cada fila es igual al valor obtenido en cada columna; el total de los ingresos de cada sector se gasta (incluyendo al ahorro). Por el lado de la producción, la totalidad de los bienes ofertados son demandados por los sectores institucionales y no hay inventarios (Robinson et al., 2001).

En México se han desarrollado diversas MCs. Banegas y Blancas (2019) emplean una MCs agregada de 2011 para analizar los efectos del gasto público sobre el crecimiento económico y el bienestar social; Núñez y Romero (2020) analizan con una MCs para 2012 el efecto de aumentar el ahorro privado y otorgar subsidios al consumo de insumos nacionales; Casares et al. (2017) emplean una MCs de 2003 que desagrega la cuenta de hogares por deciles para observar el efecto de una política fiscal y de trasferencias gubernamentales en el ingreso de los hogares; mientras que Blancas (2010) desagrega en su 
MCs la cuenta ahorro/inversión por sectores institucionales respecto a la banca central, comercial y de desarrollo, que le permite analizar la relación entre los flujos de cuenta corriente y de capital a través de lo que denomina análisis interinstitucional. Cardona et al. (2018) estiman una MCs para determinar los sectores productivos clave de la economía. Por último, Chapa et al. (2019) utilizan una MCs para evaluar la efectividad esperada del programa de apoyo a adultos mayores. Sin embargo, estos trabajos no profundizan en la metodología para elaborar una MCs para México considerado la información disponible; por lo que es importante presentar una metodología clara y estandarizada en la elaboración de una MCs que sirva como base para el análisis del desarrollo económico en el país.

El análisis de la MCs-México 2013 tiene como objetivos exponer la relación entre el sector productivo nacional y el tipo de importaciones; incluir la relación entre los sectores productivos e institucionales; y desagregar el ingresogasto de los hogares en bajo, medio y alto. La elaboración de la matriz inicia con la información de la MIP $^{3} 2013$ (INEGI, 2018a); las relaciones institucionales se calculan empleando los datos publicados del Sistema de Cuentas Nacionales-Cuenta por Sectores Institucionales (INEGI, 2013b); y empleando los resultados de la ENIGH 2014 (INEGI, 2014) se construye la estructura del sector institucional de los hogares. ${ }^{4}$ Las bases mencionadas agrupan un conjunto adicional de información oficial publicada por el INEGI (2013b y 2014).

La tabla 1 muestra la MCs prototipo dividida en tres cuadrantes. El primero integra las transacciones por concepto de consumo intermedio, ingreso de factores, impuestos indirectos e insumos importados; el segundo comprende la información referente a la demanda nacional y extranjera de bienes y servicios finales; y el tercero incluye la información correspondiente a las transferencias interinstitucionales.

Los sectores institucionales incluidos en la MCs-México 2013 son: Hogares, Sociedades financieras y no financieras públicas y privadas, Gobierno y Resto del mundo. ${ }^{5}$ La tabla 2 muestra los intercambios (ingreso-gasto) realizados entre los sectores productivos e institucionales. La diferencia entre ingresos y gastos de los sectores institucionales se considera como ahorro-inversión.

De acuerdo con la onu (1993) al no haber un método estandarizado se puede emplear la información de la MIP o de las tablas de oferta y utilización.

4 Para el caso de la ENIGH 2014 sólo se toma la estructura porcentual del ingreso/gasto por decil de los hogares y no los valores absolutos, se asume que la composición para 2014 es la misma que la de 2013.

5 El glosario de cuentas nacionales del INEGI (2018b) define las características de cada sector institucional. 


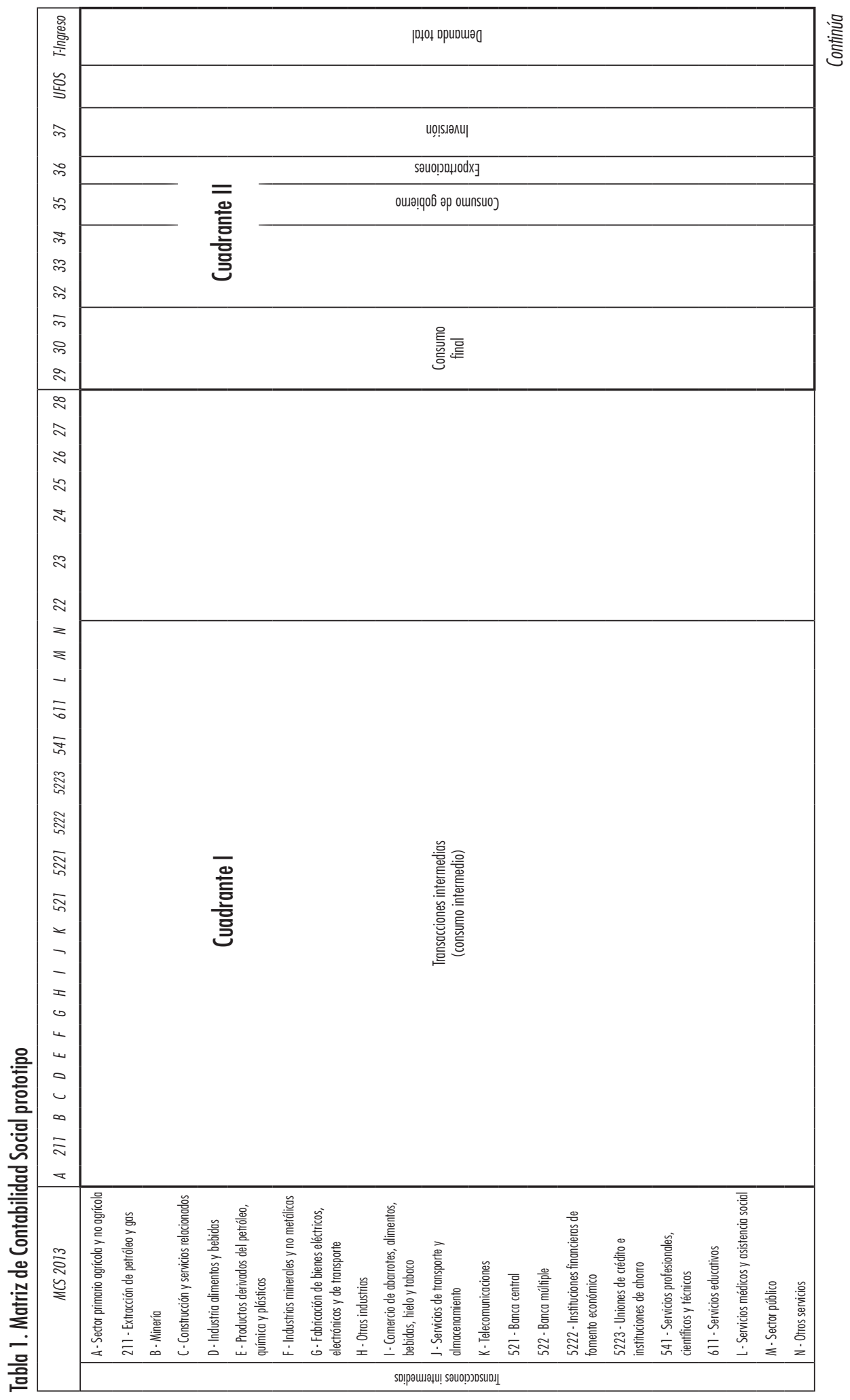




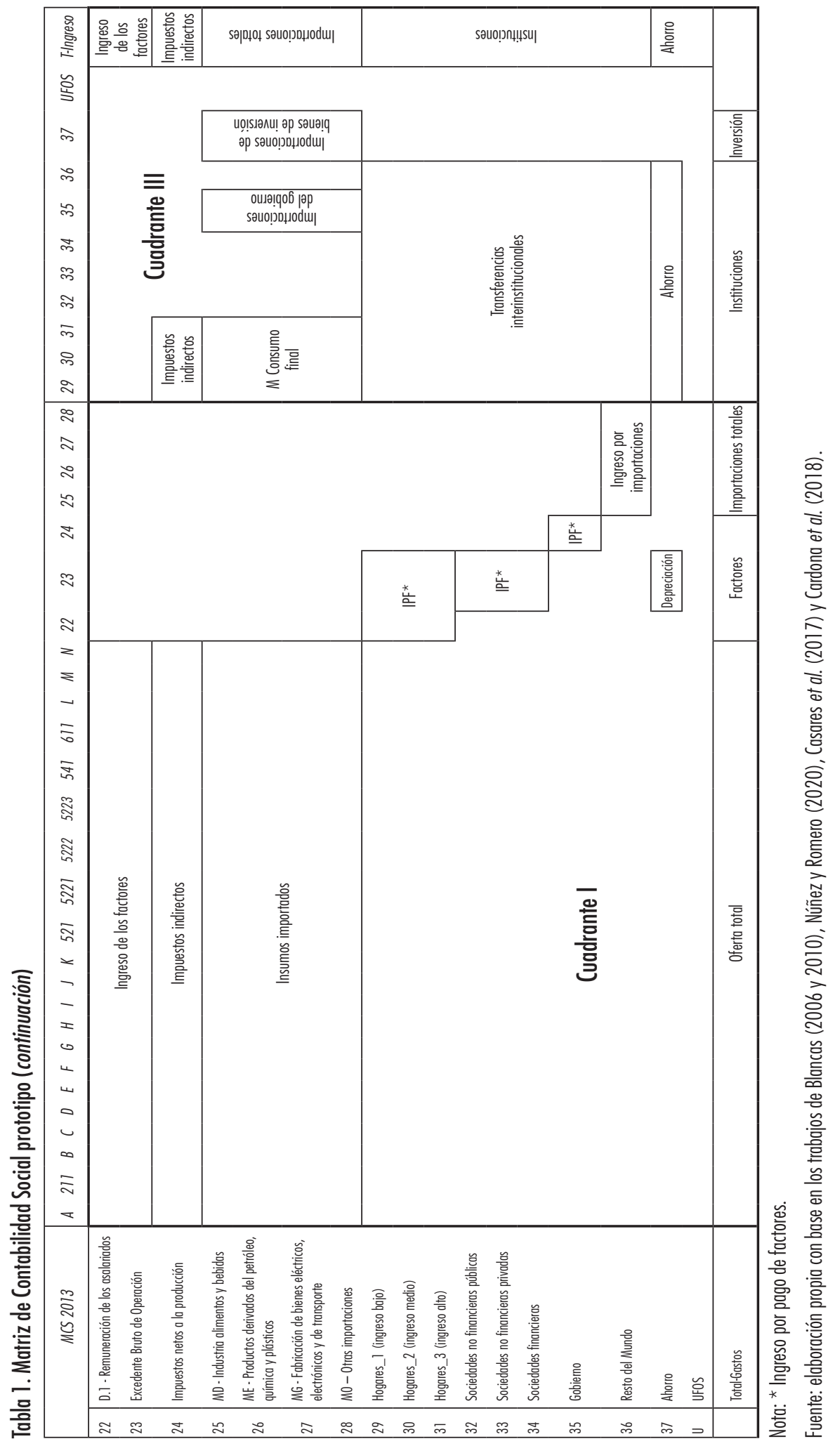


Tabla 2. Ingresos y gastos de los sectores institucionales

\begin{tabular}{|c|c|c|c|c|c|}
\hline & Gastos & & & & \\
\hline Ingresos & Sectores productivos & Hogares & Gobierno & Sociedades & Resto del mundo \\
\hline $\begin{array}{l}\text { Sectores } \\
\text { productivos }\end{array}$ & Consumo intermedio & $\begin{array}{l}\text { Consumo de } \\
\text { bienes y servicios }\end{array}$ & $\begin{array}{l}\text { Consumo del } \\
\text { gobierno }\end{array}$ & $x$ & Exportaciones \\
\hline Hogares & $\begin{array}{l}\text { Pago de } \\
\text { remuneraciones y } \\
\text { servicios del capital }\end{array}$ & $\begin{array}{l}\text { Transferencias } \\
\text { entre hogares }\end{array}$ & $\begin{array}{l}\text { Transferencias } \\
\text { sociales }\end{array}$ & $\begin{array}{l}\text { Ingresos por el pago } \\
\text { de dividendos }\end{array}$ & $\begin{array}{l}\text { Pago de servicio } \\
\text { de los factores } \\
\text { de la producción } \\
\text { en el exterior y } \\
\text { transferencias }\end{array}$ \\
\hline Gobierno & $\begin{array}{l}\text { Impuestos a la } \\
\text { producción }\end{array}$ & $\begin{array}{l}\text { Pago de } \\
\text { impuestos, } \\
\text { aprovechamientos } \\
\text { y derechos }\end{array}$ & $\begin{array}{l}\text { Transferencias } \\
\text { entre entidades } \\
\text { gubernamentales }\end{array}$ & $\begin{array}{l}\text { Impuestos sobre } \\
\text { ganancias y } \\
\text { aprovechamientos }\end{array}$ & $\begin{array}{l}\text { Aranceles a } \\
\text { importaciones y } \\
\text { transferencias }\end{array}$ \\
\hline Sociedades & $\begin{array}{l}\text { Excedente bruto de } \\
\text { operación }\end{array}$ & $\begin{array}{l}\text { Adquisición de } \\
\text { activos }\end{array}$ & $\begin{array}{l}\text { Capitalización de } \\
\text { empresas públicas } \\
\text { y transferencias a } \\
\text { empresas privadas }\end{array}$ & $\begin{array}{l}\text { Transferencias entre } \\
\text { sociedades (activos } \\
\text { y pasivos) }\end{array}$ & $\begin{array}{l}\text { Compra de activos o } \\
\text { pasivos y reinversión } \\
\text { de ganancias en } \\
\text { posesiones de no } \\
\text { residentes }\end{array}$ \\
\hline $\begin{array}{l}\text { Resto del } \\
\text { mundo }\end{array}$ & Importaciones & $\begin{array}{l}\text { Pagos } 0 \\
\text { transferencias }\end{array}$ & $\begin{array}{l}\text { Transferencias y } \\
\text { pagos de servicios } \\
\text { (ayuda humanitaria, } \\
\text { asesoría del } \\
\text { exterior) }\end{array}$ & $\begin{array}{l}\text { Pago de dividendos } \\
\text { y descapitalización } \\
\text { de las empresas } \\
\text { hacia no residentes }\end{array}$ & $x$ \\
\hline
\end{tabular}

Fuente: elaboración propia.

\section{MCS-MÉXICO 2013}

\section{Información de la MIP en la MCS}

El primer paso en la elaboración de la MCs consiste en incorporar la información de la MIP en el cuadrante I que representa la oferta total de la economía (insumos intermedios, factores productivos, importaciones totales e impuestos directos).

Las transacciones de los sectores productivos toman como base la información de la MIP que incluye 79 subsectores productivos, que se agrupan en 21 industrias dentro del cuadrante I de la MCs (véase tabla 3). Los insumos intermedios en la MIP corresponden a la demanda intermedia de los sectores productivos. 
Andrés Blancas y Rodrigo Aliphat

Tabla 3. Sectores productivos incluidos en la MCS

\begin{tabular}{|c|c|c|c|}
\hline Sector & $\begin{array}{l}\text { Sector productivo } \\
\text { (subsectores-SCIAN) }\end{array}$ & Clave-SCIAN & $\begin{array}{c}\text { Producción } \\
\text { (\% PIB) }\end{array}$ \\
\hline \multirow[t]{3}{*}{ Primario } & A-Sector primario agrícola y no agrícola & $111-115$ & 3.1 \\
\hline & 211-Extracción de petróleo y gas & 211 & 5.5 \\
\hline & B-Minería & $212-213$ & 1.6 \\
\hline \multirow[t]{6}{*}{ Secundario } & C-Construcción y servicios relacionados & $221-222$ y $236-238$ & 8.9 \\
\hline & D-Industria alimentos y bebidas & $311-312$ & 4.6 \\
\hline & E-Productos derivados del petróleo, química y plásticos & $324-326$ & 2.6 \\
\hline & F-Industrias minerales y no metálicas & $327,331-332$ & 2.0 \\
\hline & G-Fabricación de bienes eléctricos, electrónicos y de transporte & $333-336$ & 4.9 \\
\hline & H-Otras industrias & $313-316,321-323,337$ y 339 & 1.8 \\
\hline \multirow{8}{*}{$\begin{array}{l}\text { Terciario } \\
\text { (servicios) }\end{array}$} & I-Comercio de abarrotes, alimentos, bebidas, hielo y tabaco & 431 y 461 & 16.8 \\
\hline & J-Servicios de transporte y almacenamiento & $481-488$ y $491-493$ & 6.1 \\
\hline & K-Telecomunicaciones & $511-512,515$ y $517-519$ & 2.0 \\
\hline & 541-Servicios profesionales, científicos y técnicos & 541 & 1.9 \\
\hline & 611-Servicios educativos & 611 & 4.1 \\
\hline & L-Servicios médicos y asistencia social & $621-624$ & 2.4 \\
\hline & M-Sector público & 813 y 931 & 4.6 \\
\hline & $\mathrm{N}-$ Otros servicios & $\begin{array}{l}5224-5225,523-524,531- \\
533,551,561-562,711-713 \\
721-722,811-812 \text { y } 814\end{array}$ & 20.9 \\
\hline \multirow{4}{*}{$\begin{array}{l}\text { Terciario } \\
\text { (financiero) }\end{array}$} & 521-Banca central & 521 & 0.1 \\
\hline & 5221-Banca múltiple & 5221 & 1.8 \\
\hline & 5222-Instituciones financieras de fomento económico & 5222 & 0.3 \\
\hline & 5223-Uniones de crédito e instituciones de ahorro & 5223 & 0.2 \\
\hline
\end{tabular}

Fuente: elaboración propia con datos del SCIAN (INEGI, 2013a) y MIP (INEGI, 2018a).

Los factores productivos son el trabajo y capital disponible para la producción de bienes y servicios. El ingreso/pago a los factores de la producción (IPF-renglones 22 y 23) se descompone en remuneraciones de los asalariados (w) y en Excedente Bruto de Operación (вво):

$$
I P F=W+E B O
$$


La información sobre importaciones se obtiene de la MIP de bienes y servicios importados por sector productivo. La MCs-México 2013 desagrega a las importaciones de la cuenta del resto del mundo. Un ejercicio similar realiza Blancas (2006) cuando desagrega la cuenta de ahorro-financiero con el objetivo de analizar la relación entre el sector financiero y la economía real.

La MIP desagregada por requerimientos importados permite identificar la demanda de importaciones. En la tabla 4 se desagregan las importaciones en cuatro categorías: las primeras tres representan más del $92 \%$ de las importaciones totales y por su alta demanda de los hogares se incluye a MD-Industrias de alimentos y bebidas.

Las importaciones totales se integran en la MCs como la suma de las importaciones por tipo de demanda: bienes importados intermedios $\left(M_{I n t}\right)$, hogares $\left(M_{C o n s}\right)$, gobierno $\left(M_{G o b}\right)$ e inversión o formación bruta de capital fijo $\left(M_{F B K F}\right)$.

$$
M=M_{\text {Int }}+M_{\text {Cons }}+M_{G o b}+M_{F B K F}
$$

La suma de los cuatro tipos de importación equivale al ingreso en la cuenta del resto del mundo. Para cumplir con la regla contable de partida doble de ingreso-gasto, la cuenta de importaciones se salda con ingresos por importaciones para el resto del mundo (véase tabla 3, renglón 36, columnas 25-28).

Los impuestos y subsidios a la producción e importaciones registrados en la MIP corresponden a los impuestos indirectos (INEGI, 2018a); en la MCS se incluyen como Impuestos netos a la producción (renglón 24).

La suma de transacciones intermedias, ingreso de factores, importación de insumos e impuestos indirectos representa la oferta total de la economía (véase ecuación 3).

Oferta total $=$ Insumos + Pago de factores $+M_{\text {intermedios }}+T_{\text {indirectos }}$

El cuadrante II integra el consumo intermedio de los sectores productivos (insumos), demanda de hogares, gobierno, exportaciones y formación bruta de capital fijo (FBKF). Las variaciones de existencias son valores que no se reportan en la MIP $^{6}$ y se incluyen dentro de la MCS como UFOS (renglón/ columna 38).

6 La información de la MIP no permite determinar la demanda de bienes y servicios de periodos anteriores o futuros. 
Andrés Blancas y Rodrigo Aliphat

Tabla 4. Importaciones por sectores productivos incluidos en la MCS

\begin{tabular}{llc}
\hline Industrias & \multicolumn{1}{c}{ SCIAN } & Importaciones (\% total) \\
\hline MD-Industria alimentos y bebidas & 311 y 312 & 4.34 \\
ME-Productos derivados del petróleo, química y plásticos & 324,325 y 326 & 21.85 \\
MG-Fabricación de bienes eléctricos, electrónicos y de transporte & $333,334,335$ y 336 & 66.44 \\
MO-Otras importaciones & NA & 7.37 \\
\hline
\end{tabular}

Fuente: elaboración propia con información de INEGI (2013a).

Al sumar la demanda intermedia con la demanda por sectores institucionales e inversión (FBKF) se obtiene la demanda final por sector productivo. La suma de la demanda final por sector productivo representa la demanda agregada nacional.

Demanda total $=$ Insumos $+C+G+X+F B K F$

Y como identidad contable o condición de equilibrio se comprueba que la oferta total es igual a la demanda total:

Oferta total $=$ Demanda total

\section{Información del Sistema de Cuentas Institucionales en la MCS}

Para determinar los valores del cuadrante III se desagregan las transferencias monetarias realizadas entre sectores institucionales empleando la base de datos de la Cuenta por Sectores Institucionales (CsI).

El primer paso consiste en trasformar el pago total de los factores productivos en ingresos de los sectores institucionales (renglón/columnas 22 y 23). El pago de remuneraciones $(W$ ) se obtiene de la Csi como D.1-Remuneraciones de los asalariados e incluye las subcuentas D.11-Sueldos y salarios y D.12Contribuciones sociales de los empleadores; la información se registra en la MCs como ingreso de hogares (renglones 29-31).

$W=$ Remuneraciones de los asalariados $\rightarrow$ Hogares

El pago a las subcuentas B.2b-Excedente bruto de operación (Ево) у B.3bIngreso mixto bruto se distribuye entre todos los sectores institucionales y la 
Tabla 5. Distribución del EBO por sector institucional (millones de pesos a precios de 2013)

\begin{tabular}{|c|c|c|c|}
\hline $\begin{array}{l}\text { Sector } \\
\text { institucional }\end{array}$ & $\begin{array}{l}\text { B.2b-Excedente } \\
\text { bruto de operación }\end{array}$ & $\begin{array}{l}\text { P.51 c1-Consumo de capital } \\
\text { fijo sobre excedente bruto } \\
\text { de operación }\end{array}$ & $\begin{array}{l}\text { B.2n-Excedente } \\
\text { neto de } \\
\text { operación }\end{array}$ \\
\hline S.11001-Sociedades no financieras públicas & 1222276 & 477211 & 745065 \\
\hline S. 11002,03 -Sociedades no financieras privadas ${ }^{0}$ & 4416063 & 1388378 & 3027685 \\
\hline S.12-Sociedades financieras & 397751 & 22402 & 375349 \\
\hline S.13-Gobierno general & 8657 & 8657 & 0 \\
\hline S.14-Hogares, ${ }^{b}, c$ & 4967600 & 670582 & 4297018 \\
\hline S.2-Resto del mundo & NA & NA & NA \\
\hline \multicolumn{4}{|c|}{$\begin{array}{l}\text { Notas: }{ }^{a} \text { S. } 11002 \text { y S. } 11003 \text {-Sociedades no financieras privadas nacionales y de control extranjero; }{ }^{b} \text { Incluye B.3b-Ingreso } \\
\text { mixto bruto, P.51 c2-Consumo de capital fijo sobre ingreso mixto bruto y B.3n-Ingreso mixto neto; }{ }^{C} \text { Incluye a las S.15-Institu- } \\
\text { ciones sin fines de lucro al servicio de los hogares (ISFLSH); NA: No Aplica. } \\
\text { Fuente: elaboración propia con datos del INEGI, } 2013 \text { b. }\end{array}$} \\
\hline
\end{tabular}

depreciación (véase información de la tabla 5). La suma del вво y los salarios reportados en la CSI es igual al valor reportado en la MIP.

La cuenta de Impuestos netos a la producción (renglón 24) incluye los impuestos indirectos pagados por los hogares como el Impuesto al Valor Agregado (IVA), impuestos por exportaciones e inversión; el valor total se transfiere al gobierno como ingreso (renglón 35/columna 24).

El valor agregado bruto generado en la economía se traslada a los sectores institucionales como pago de remuneraciones, impuestos netos a la producción y excedente bruto de operación (columnas 22-24). De igual manera, el pago por concepto de depreciación se resta del Ево y se transfiere a la cuenta de ahorro (renglón 33).

El siguiente paso en la construcción de la MCs es transferir el pago por importaciones de insumos intermedios, de capital y de consumo del sector productivo, hogares, gobierno e inversión (renglones 24-27) a la cuenta del resto del mundo (renglón 38/columnas 24-27).

Con el registro del pago de importaciones de los residentes al resto del mundo se concluyen los intercambios entre el sector productivo y los sectores institucionales; además, se concilió en la MCs la información de la MIP con la CSI. La forma en que se ha ordenado la información garantiza que la MCs sea cuadrada y que la suma del gran total de las columnas y filas sea igual. 


\section{Matriz de transferencias institucionales}

Finalmente, se incluyen en el cuadrante III la Matriz de Transferencias Interinstitucionales (MTI). Esta matriz se construye agregando los intercambios interinstitucionales reportados en la sección II-Cuenta de distribución y utilización del ingreso y en la subsección II.1.2-Cuenta de asignación del ingreso primario del CSI. Se registran también los intercambios por el concepto de D.4-Renta de la propiedad, D.5-Impuestos corrientes sobre el ingreso, riqueza, etcétera, y D.7-Otras transferencias corrientes.

El método empleado para estimar los pagos entre sectores institucionales consiste en identificar sus transacciones respecto del resto de los sectores. Para determinar cada transacción se desagrega la Csi a nivel de subsector institucional y las subcuentas al máximo nivel de desagregación. A manera de ejemplo, sobre cómo se registra cada transferencia de la csi, la tabla 6 muestra las trasferencias de la subcuenta D.5-Impuestos corrientes sobre el ingreso, riqueza, etcétera, y se observa que los sectores institucionales transfieren recursos al sector S.13-Gobierno general por el concepto de impuestos corrientes.

Tabla 6. Transferencias interinstitucionales de la subcuenta D.5-Impuestos corrientes sobre el ingreso, riqueza, etcétera (millones de pesos a precios de 2013)

\begin{tabular}{|c|c|c|}
\hline Sector institucional & U-Usos & R-Recursos \\
\hline S.11001-Sociedades no financieras públicas & 10642 & \\
\hline S.11002,03-Sociedades no financieras privadas ${ }^{a}$ & 466955 & \\
\hline S.12-Sociedades financieras & 28342 & \\
\hline S.13-Gobierno general & & 1062905 \\
\hline S.14-Hogares ${ }^{b}$ & 556966 & \\
\hline S.2-Resto del mundo & NA & NA \\
\hline Total & 1062905 & 1062905 \\
\hline
\end{tabular}

Los intercambios de la cuenta D.5 se presentan de manera matricial en la tabla 7 , esta submatriz es un ejemplo del conjunto de submatrices que conforman la MTI. 
Tabla 7. Submatriz de transferencias interinstitucionales de la cuenta D.5-Impuestos corrientes sobre el ingreso, riqueza, etcétera (millones de pesos a precios de 2013)
5.11001
$5.11002,03$
S.12
5.13
S. 14
S.2
Total

S.11001-Sociedades no

financieras públicas

S.11002,03-Sociedades no

financieras privadas

S.12-Sociedades financieras

S.13-Gobierno general

$10642 \quad 466955 \quad 28342$

556966

1062905

S.14-Hogares

S.2-Resto del mundo

\begin{tabular}{llllll}
\hline Total & 10642 & 466955 & 28342 & 556966 & 1062905 \\
\hline
\end{tabular}

Nota: cifras redondeadas.

Fuente: elaboración propia con datos de la tabla 6.

La MTI se concluye sumando la información de cada submatriz (véase tabla 8), la cual contiene la información requerida en el cuadrante III de la MCS.

Tabla 8. Matriz de transferencias institucionales (millones de pesos a precios de 2013)

\begin{tabular}{lrrrrrrr}
\hline Sector institucional & S.11001 & S.11002,03 & \multicolumn{1}{c}{ S.12 } & \multicolumn{1}{c}{ S.13 } & S.14 & \multicolumn{1}{c}{ S.2 } & Total \\
\hline $\begin{array}{l}\text { S.11001-Sociedades no } \\
\text { financieras públicas }\end{array}$ & 836 & 9988 & 6633 & 8015 & 4159 & 563 & 30195 \\
$\begin{array}{l}\text { S.11002,03-Sociedades no } \\
\text { financieras privadas }\end{array}$ & 6971 & 83284 & 98562 & 40586 & 114176 & 55775 & 399353 \\
S.12-Sociedades financieras & 25630 & 292938 & 180930 & 162800 & 386054 & 43159 & 1091511 \\
S.13-Gobierno general* & 886549 & 653499 & 68012 & 2244131 & 972079 & 1698 & 4825968 \\
S.14-Hogares & 14786 & 2672026 & 318587 & 1357046 & 31919 & 344070 & 4738433 \\
S.2-Resto del mundo & 24320 & 412414 & 66469 & 143225 & 12841 & 0 & 659269 \\
\hline Total & 959092 & 4124148 & 739192 & 3955804 & 1521228 & 445264 & 11744729 \\
\hline
\end{tabular}

Notas: S. 11002 y S. 11003 -Sociedades no financieras privadas nacionales y de control extranjero; Incluye a las S.15-Instituciones sin fines de lucro al servicio de los hogares (ISFLSH). Cifras redondeadas. *En la cuenta de gobierno general (ingresos) se encontró un valor fuera de la matriz de 3 974. Este dato es reportado por INEGI en la subcuenta D.7-Otras transferencias corrientes.

Fuente: elaboración propia con datos del INEGI (2013b) y Banco de México (2013). 


\section{Desagregación de la cuenta de hogares}

De acuerdo con Cortés (2018) y Nava y Brown (2018) en México persisten problemas de distribución del ingreso, por lo que considerar un solo tipo de hogar supondría pensarlos homogéneos. Siguiendo la metodología de Blancas (2006 y 2010) y Casares et al. (2017) se desagrega el sector institucional de los hogares en los siguientes tres grupos: de ingreso bajo (deciles I-IV), medio (V-VIII) y alto (IX-X). Para desagregar la cuenta de hogares se toma como referencia la composición del ingreso/gasto por decil de la ENIGH 2014 (INEGI, 2014); se sigue una técnica de clasificación similar a la presentada por Leyva (2004, p. 30).

Desagregar la cuenta de hogares es fundamental para el estudio de la distribución del ingreso-gasto de los hogares y su vínculo con el desarrollo económico. En la actualidad se reconocen diversas investigaciones que abordan el problema de homogeneización y uso de los datos sobre distribución del ingreso; ejemplo de lo anterior son Bustos y Leyva (2017) quienes muestran las discrepancias en la medición de la distribución del ingreso por el lado de cuentas nacionales respecto de la ENIGH e incluso señalan un posible problema de subestimación de algunos datos. Para esta investigación se decidió tomar como referencia los datos de la ENIGH debido a que la estimación del ingreso de los hogares por el lado de cuentas nacionales se centra en la construcción de agregados macroeconómicos, mientras que la encuesta tiene un marcado uso para reconocer la distribución del ingreso entre los hogares (Villatoro, 2015, p. 11). Por esta razón, se emplea la información por decil de ingreso de los hogares de la ENIGH-2014 para formar tres grupos de hogares (bajo, medio y alto) agrupando los deciles de la encuesta por tipo de hogar (véase tabla 9). Es importante señalar que los hogares "de ingreso bajo" tienen un saldo negativo de su ingreso-gasto corriente, por lo que la MCs-México 2013 refleja un ahorro negativo en este grupo.

Tabla 9. Agregación de hogares por decil de ingreso, ENIGH 2014 (gasto trimestral miles de pesos corrientes 2014)

\begin{tabular}{lcccc}
\hline Deciles & \% de hogares & Ingreso corriente total & Gasto corriente total & Saldo \\
\hline I al IV & 19.2 & 183027 & 209831 & -26804 \\
V al VIII & 36.1 & 432166 & 394935 & 37230 \\
IX al X & 44.8 & 642752 & 490520 & 152232 \\
\hline
\end{tabular}

Fuente: elaboración propia con datos de la ENIGH, 2014. 
La desagregación por hogar de ingreso bajo, medio y alto en la MCs se resuelve multiplicando los valores de ingreso/gasto de la cuenta de hogares por el porcentaje de ingreso/gasto reportado en la ENIGH; se toma la composición porcentual del gasto de los hogares y se concilia con el valor absoluto del ingreso/gasto de la cuenta de hogares de la MCs.

Con los tabulados de la ENIGH 2014 se concilia la información del ingreso por tipo de hogar con las transferencias de recursos que reciben los hogares del resto de los sectores institucionales (véase tabla 10); se construyen proxys de los valores reportados en la ENIGH que se incluyen dentro de la MCs. Por ejemplo, el pago de remuneraciones registrado en la MCs-México 2013 corresponde en la ENIGH al ingreso de los hogares por concepto de Remuneraciones por trabajo subordinado, Ingresos por trabajo independiente e Ingresos de otros trabajos. Por lo tanto, la proporción de este ingreso concentrada en los deciles I al IV (11.23\%) es un proxy de la proporción de ingreso por concepto de Pago de Remuneraciones de los Hogares de Ingreso Bajo (renglón 25/columna 22). Leyva (2004, p. 30) realiza una estimación similar para ajustar la información de cuentas nacionales con la ENIGH.

Tabla 10. Transferencias institucionales de la SAM prototipo y rubros de ingreso de hogares (ENIGH)

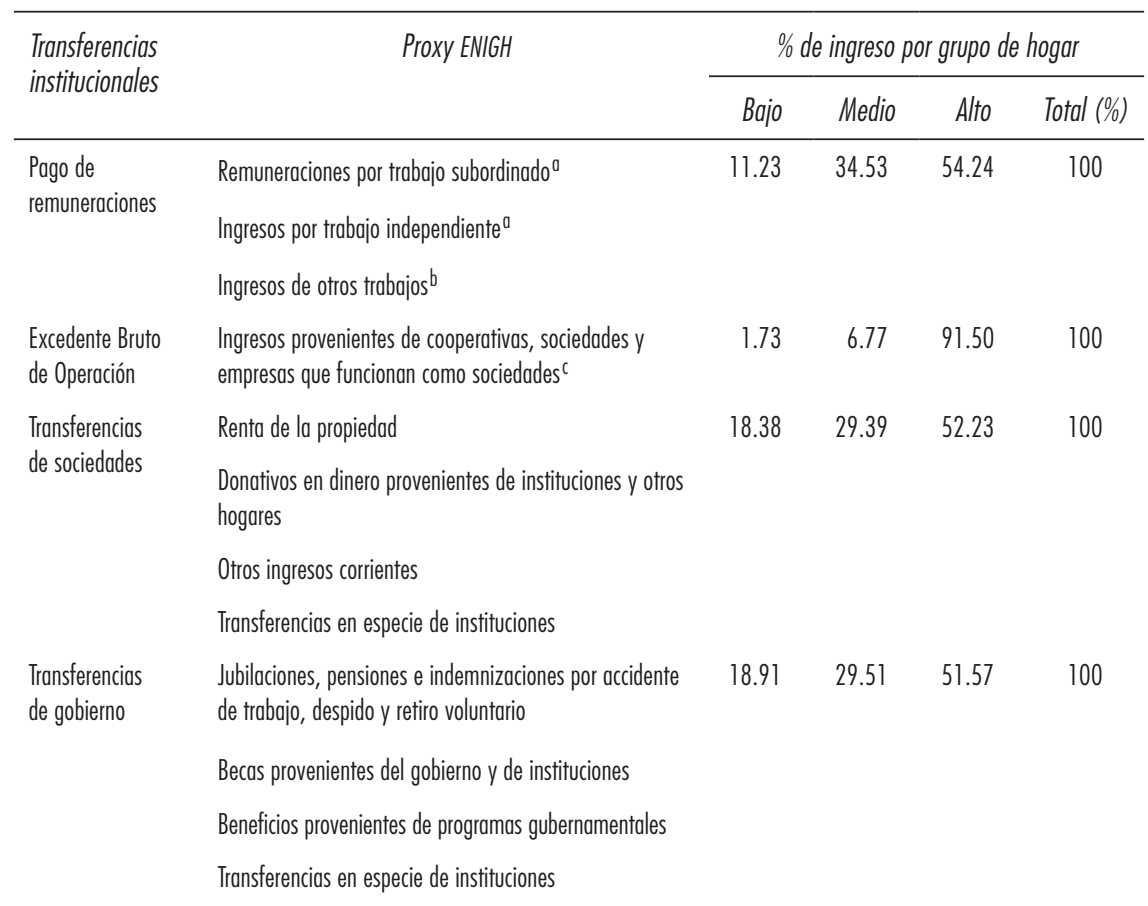


Tabla 10. Transferencias institucionales de la SAM prototipo y rubros de ingreso de hogares (continuación)

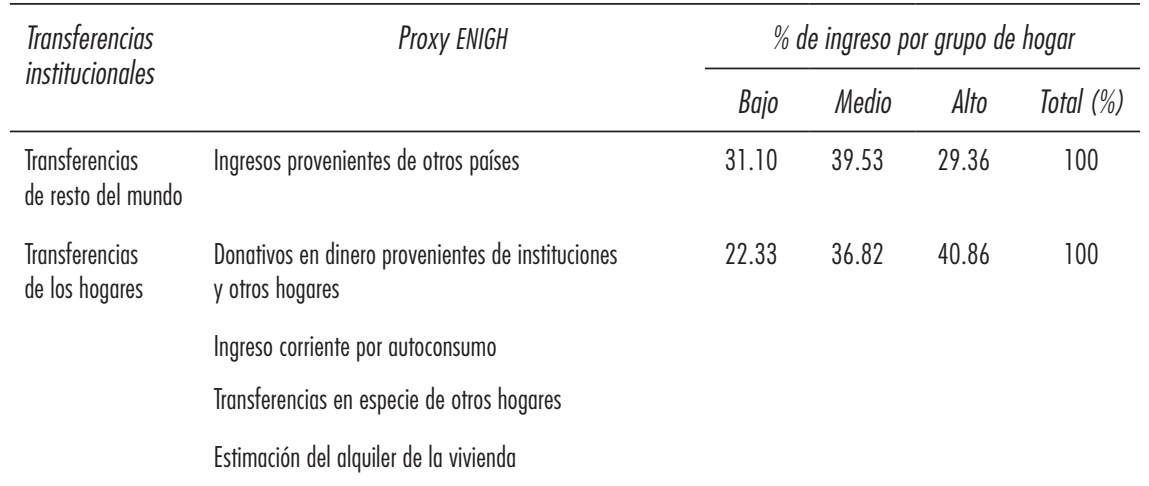

Notas: Incluye sólo el ingreso por trabajo principal y secundario; b Incluye el ingreso de los trabajos 3 al 7 y el ingreso obtenido en el periodo de referencia por otros trabajos realizados fuera del periodo; ' Incluyen las ganancias y utilidades de las empresas constituidas en sociedad, cooperativas y cuasi sociedades.

Fuente: elaboración propia con datos de la ENIGH, 2014.

La estimación de los gastos por tipo de hogar sigue la misma desagregación de los ingresos (véase tabla 11). Se consideran cuatro grupos: Gasto en bienes de consumo final nacionales, Importación de bienes de consumo final, Pago de impuestos indirectos y Transferencias al resto de los sectores institucionales que representan proxys del gasto de la cuenta de hogares de la MCs.

Con las tablas 10 y 11 se completa la información necesaria para concluir la MCs-México 2013 (véase tabla 12).

\section{Tabla 11. Transferencias institucionales y gasto de hogares}

\begin{tabular}{|c|c|c|c|c|c|}
\hline \multirow[t]{2}{*}{ Consumo final } & \multirow[t]{2}{*}{ Proxy ENIGH } & \multicolumn{4}{|c|}{$\%$ de gasto por tipo de hogar } \\
\hline & & Bajo & Medio & Alto & Total (\%) \\
\hline A-Sector primario agrícola y no agrícola & Alimentos, bebidas y tabaco (ABT) & 25.20 & 40.47 & 34.33 & 100 \\
\hline 211-Extracción de petróleo y gas & NA & NA & NA & NA & NA \\
\hline B-Minería & $\begin{array}{l}\text { Gasto total de los hogares en bienes de } \\
\text { consumo (GTHBC) }\end{array}$ & 18.41 & 35.23 & 46.37 & 100 \\
\hline C-Construcción y servicios relacionados & $\begin{array}{l}\text { Servicios y materiales para reparación, } \\
\text { mantenimiento y/o ampliación de la vivienda }\end{array}$ & 14.37 & 26.00 & 59.63 & 100 \\
\hline D-Industria alimentos y bebidas & ABT & 25.20 & 40.47 & 34.33 & 100 \\
\hline $\begin{array}{l}\text { E-Productos derivados del petróleo, } \\
\text { química y plásticos }\end{array}$ & $\begin{array}{l}\text { Vivienda, servicios de conservación, energía } \\
\text { elécrica y combustibles } \\
\text { Artículos y servicios para la limpieza, cuidados } \\
\text { de la casa, enseres domésticos y muebles, } \\
\text { cristalería, utensilios domésticos y blancos }\end{array}$ & 21.23 & 37.53 & 41.24 & 100 \\
\hline
\end{tabular}




\begin{tabular}{|c|c|c|c|c|c|}
\hline \multirow[t]{2}{*}{ Consumo final } & \multirow[t]{2}{*}{ Proxy ENIGH } & \multicolumn{4}{|c|}{$\%$ de gasto por tipo de hogar } \\
\hline & & Bajo & Medio & Alto & Total (\%) \\
\hline F-Industrias minerales y no metálicas & GTHBC & 18.41 & 35.23 & 46.37 & 100 \\
\hline $\begin{array}{l}\text { G-Fabricación de bienes eléctricos, } \\
\text { electrónicos y de transporte }\end{array}$ & $\begin{array}{l}\text { Transporte; adquisición, mantenimiento, } \\
\text { accesorios y servicios para vehículos; } \\
\text { comunicaciones (TAMASVC) }\end{array}$ & 13.82 & 36.60 & 49.58 & 100 \\
\hline H-Otras industrias & GTHBC & 18.41 & 35.23 & 46.37 & 100 \\
\hline $\begin{array}{l}\text { I-Comercio de abarrotes, alimentos, } \\
\text { bebidas, hielo y tabaco }\end{array}$ & ABT & 25.20 & 40.47 & 34.33 & 100 \\
\hline J-Servicios de transporte y almacenamiento & TAMASVC & 13.82 & 36.60 & 49.58 & 100 \\
\hline K-Telecomunicaciones & GTHBC & 18.41 & 35.23 & 46.37 & 100 \\
\hline 521-Banca central & $\mathrm{NA}$ & NA & & & \\
\hline 5221-Banca múltiple & $\begin{array}{l}\text { Pago por tarjeta de crédito al banco o casa } \\
\text { comercial }\end{array}$ & 2.12 & 14.21 & 83.67 & 100 \\
\hline $\begin{array}{l}\text { 5222-Instituciones financieras de fomento } \\
\text { económico }\end{array}$ & $\begin{array}{l}\text { Depósito en cuenta de ahorros, tandas, cajas } \\
\text { de ahorro, etcétera }\end{array}$ & 8.55 & 18.21 & 73.24 & 100 \\
\hline $\begin{array}{l}\text { 5223-Uniones de crédito e instituciones } \\
\text { de ahorro }\end{array}$ & $\begin{array}{l}\text { Depósito en cuenta de ahorros, tandas, cajas } \\
\text { de ahorro, etcétera }\end{array}$ & 8.55 & 18.21 & 73.24 & 100 \\
\hline $\begin{array}{l}\text { 541-Servicios profesionales, científicos } \\
\text { y técnicos }\end{array}$ & GTHBC & 18.41 & 35.23 & 46.37 & 100 \\
\hline 611-Servicios educativos & $\begin{array}{l}\text { Servicios de educación, artículos educativos, } \\
\text { artículos de esparcimiento y otros gastos de } \\
\text { esparcimiento }\end{array}$ & 11.27 & 28.28 & 60.45 & 100 \\
\hline L-Servicios médicos y asistencia social & Cuidados de la salud & 17.12 & 27.94 & 54.95 & 100 \\
\hline M-Sector público & GTHBC & 18.41 & 35.23 & 46.37 & 100 \\
\hline N-Otros servicios & GTHBC & 18.41 & 35.23 & 46.37 & 100 \\
\hline \multicolumn{6}{|l|}{ Importación de bienes de consumo final } \\
\hline Tipo de bienes importados & Proxy ENIGH & Bajo & Medio & Alto & Total \\
\hline MD-Industria alimentos y bebidas & ABT & 25.20 & 40.47 & 34.33 & 100 \\
\hline $\begin{array}{l}\text { ME-Productos derivados del petróleo, } \\
\text { química y plásticos }\end{array}$ & $\begin{array}{l}\text { Vivienda, servicios de conservación, energía } \\
\text { eléctrica y combustibles }\end{array}$ & 21.23 & 37.53 & 41.24 & 100 \\
\hline $\begin{array}{l}\text { MG-Fabricación de bienes eléctricos, } \\
\text { electrónicos y de transporte }\end{array}$ & TAMASVC & 13.82 & 36.60 & 49.58 & 100 \\
\hline MO-Otras importaciones & GTHBC & 18.41 & 35.23 & 46.37 & 100 \\
\hline \multicolumn{6}{|l|}{ Impuestos al consumo } \\
\hline Pago de impuestos & GTHBC & 18.41 & 35.23 & 46.37 & 100 \\
\hline \multicolumn{6}{|l|}{ Transferencias interinstitucionales } \\
\hline Transferencias institucionales & Transferencias de gasto & 8.42 & 28.57 & 63.01 & 100 \\
\hline
\end{tabular}

Nota: NA: № Aplica.

Fuente: elaboración propia con datos de la ENIGH, 2014. 


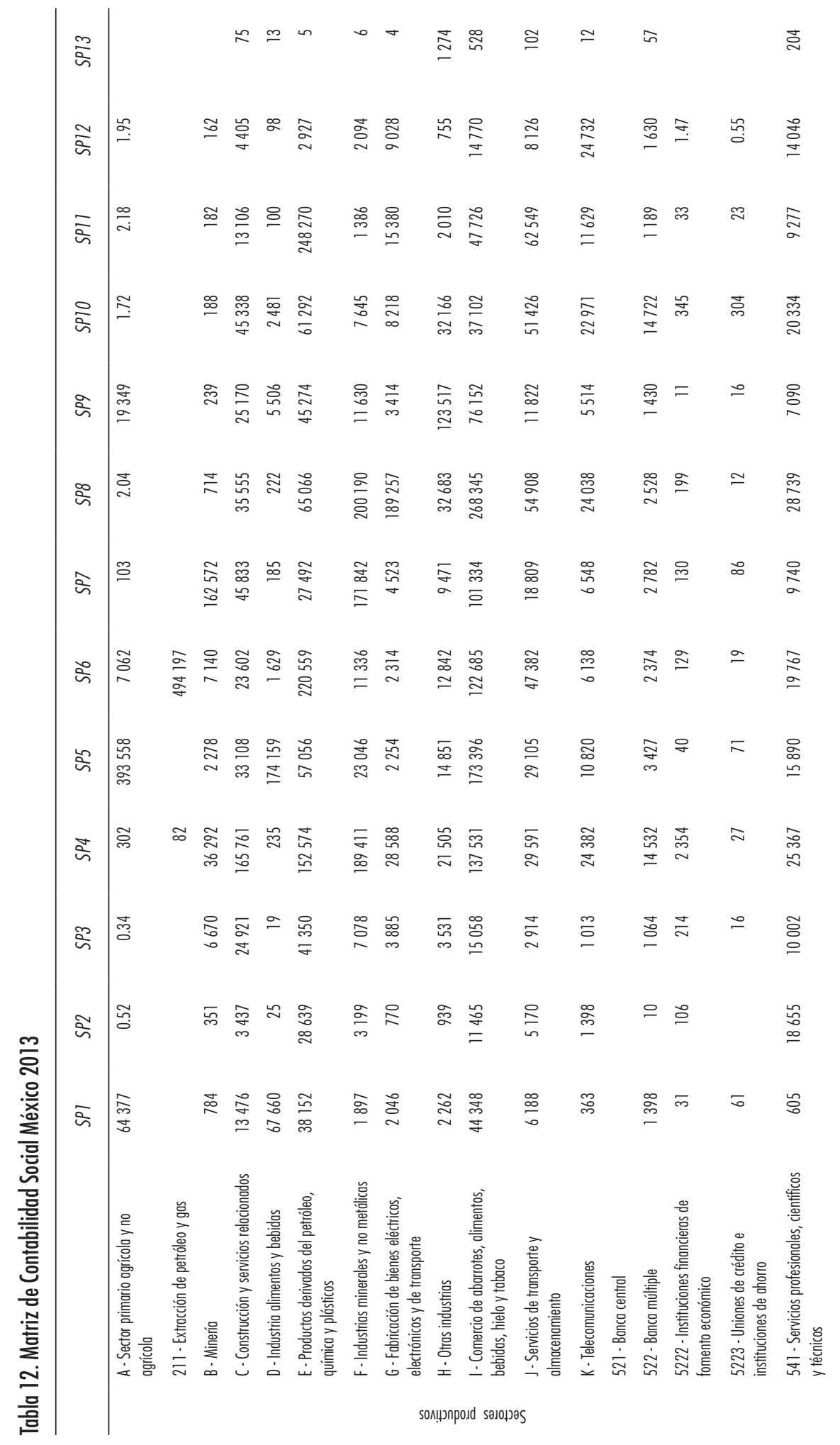




$$
\begin{aligned}
& \text { m్ }
\end{aligned}
$$

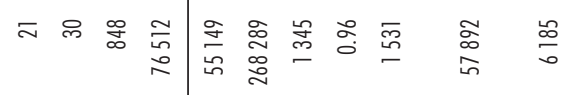

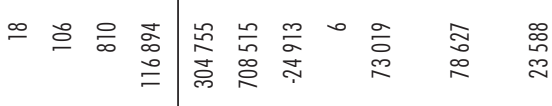

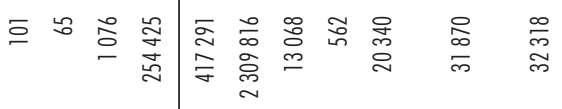

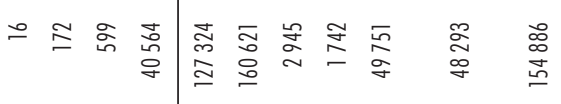

$$
\begin{aligned}
& \text { 四 }
\end{aligned}
$$

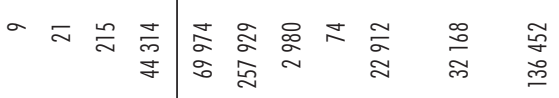

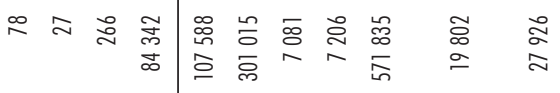

$$
\begin{aligned}
& \text { в }
\end{aligned}
$$

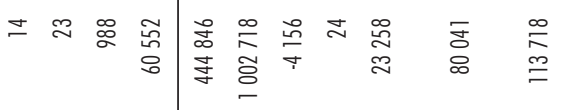

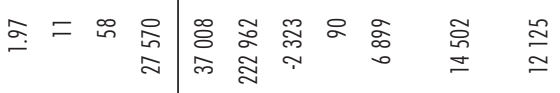

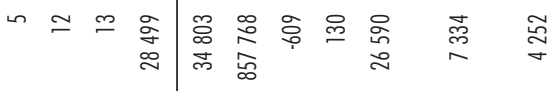

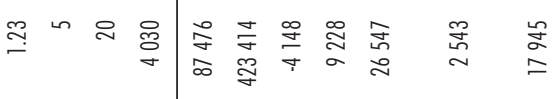

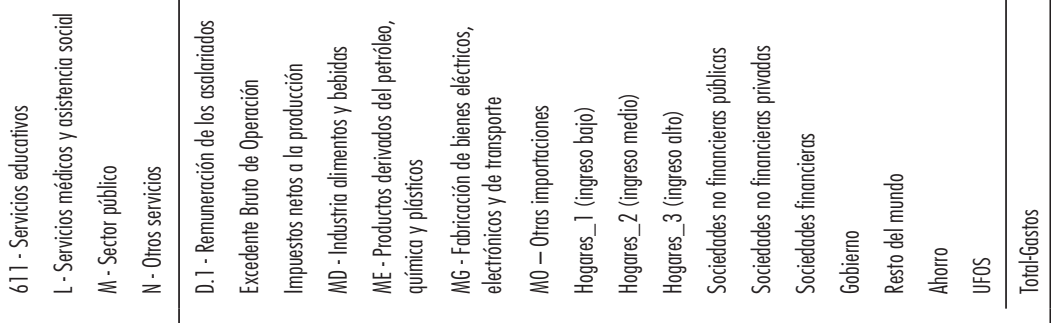

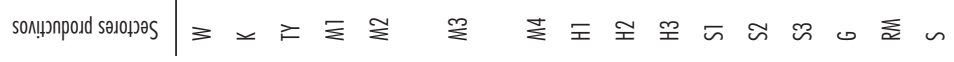




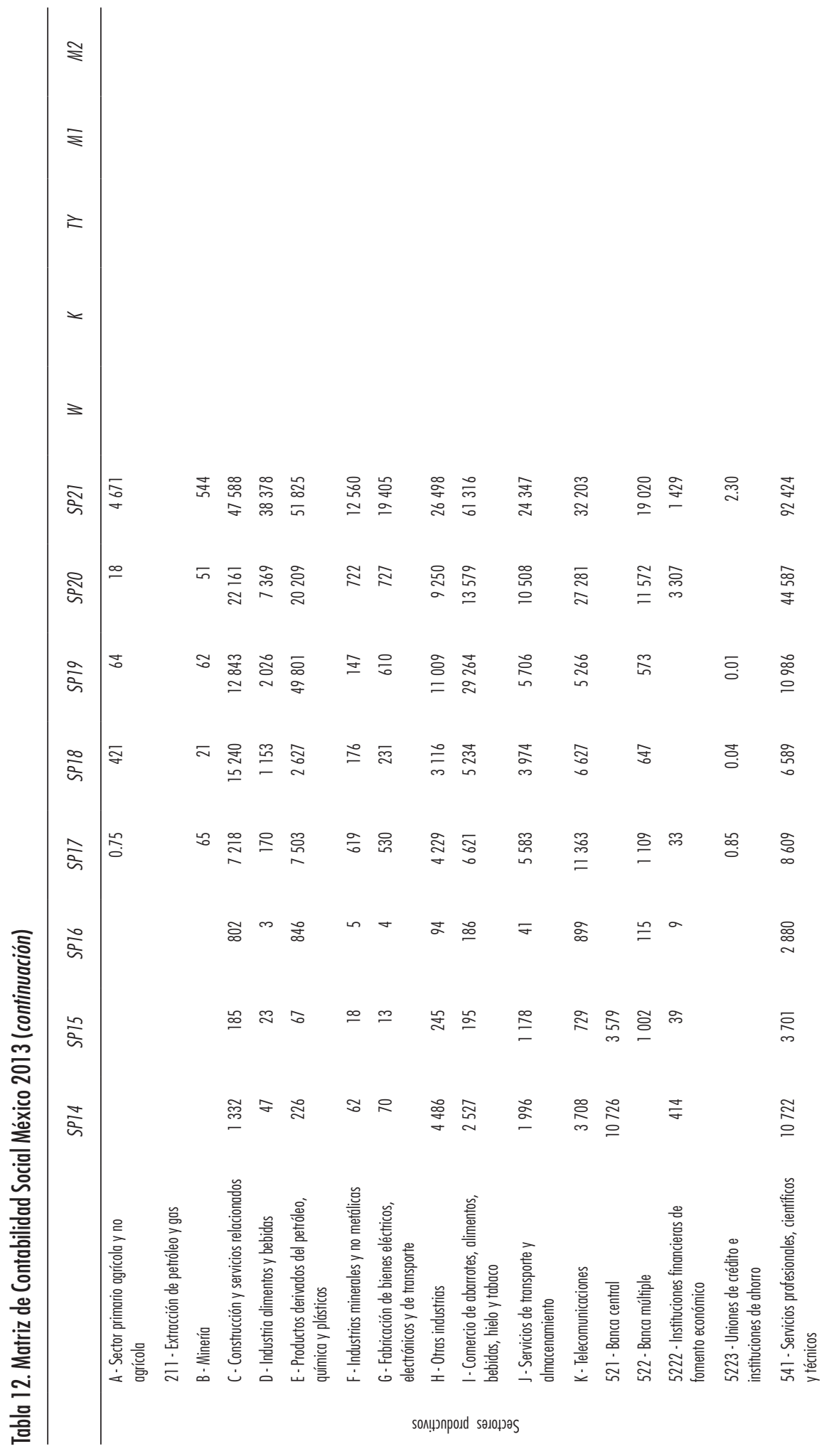




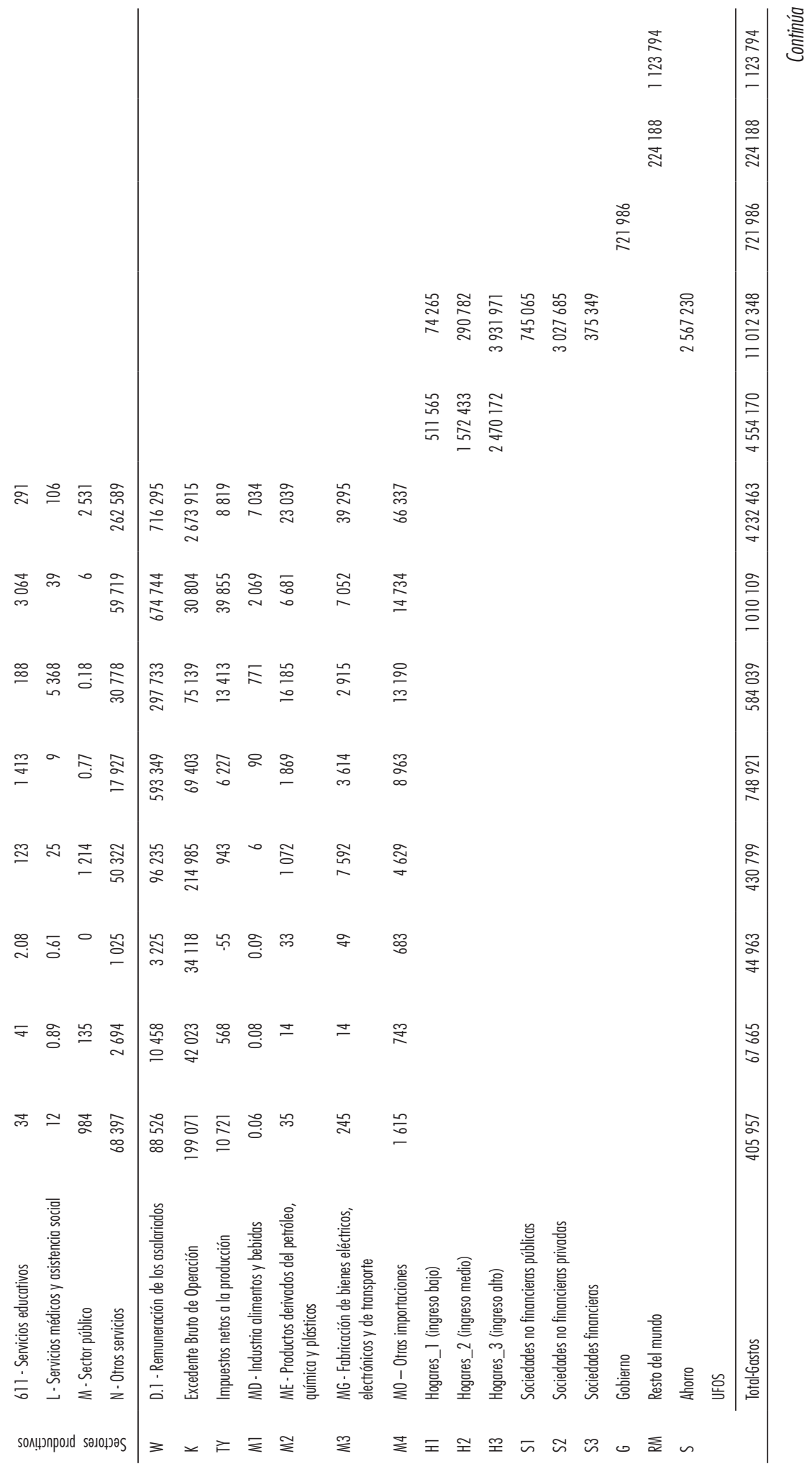




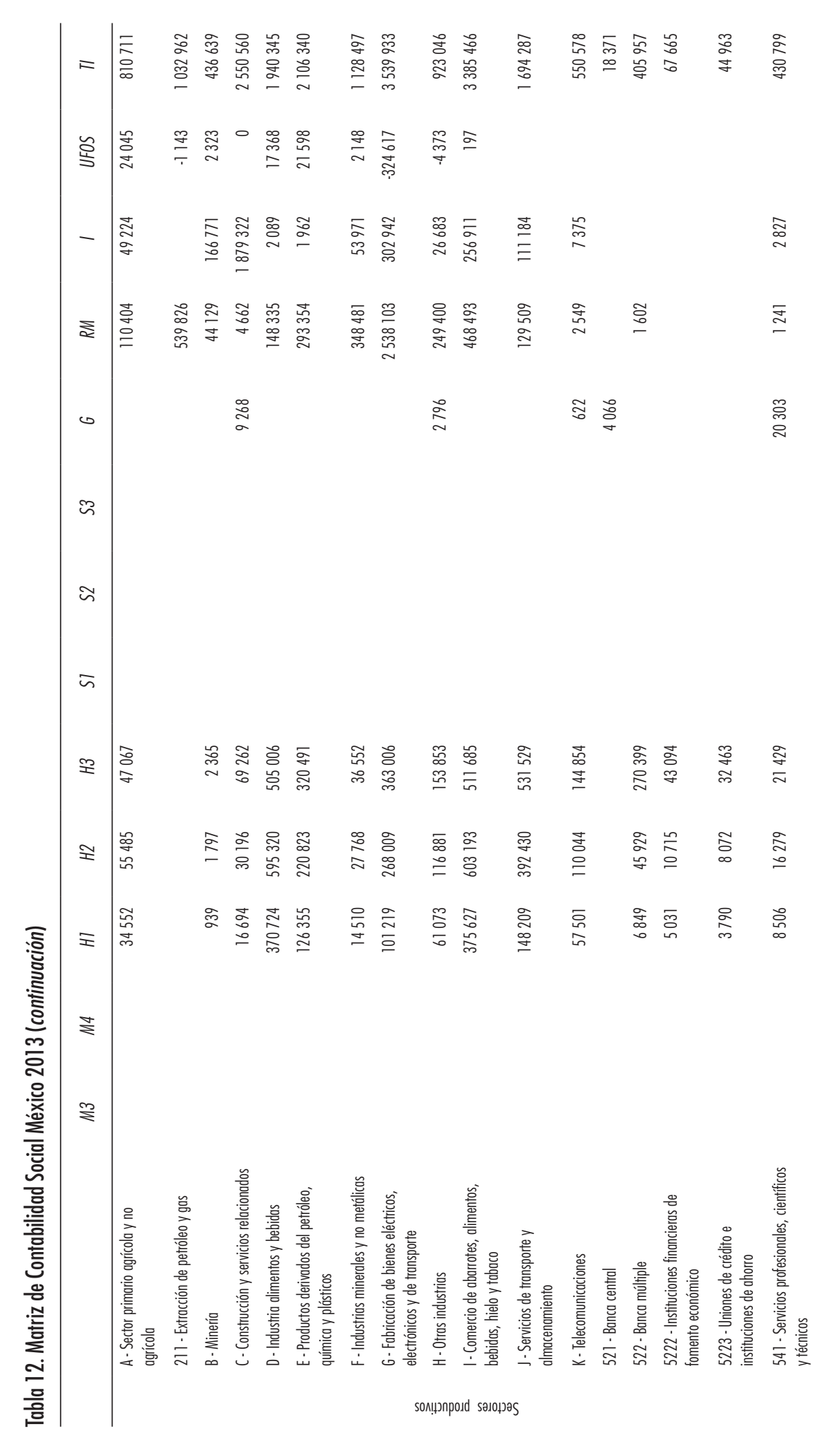




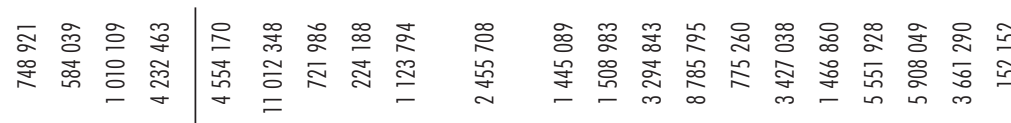

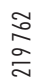

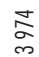

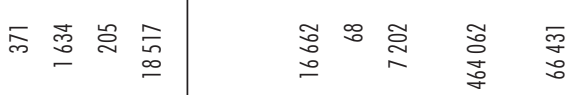

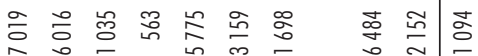

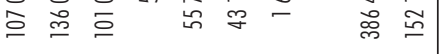

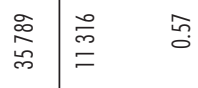

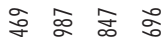

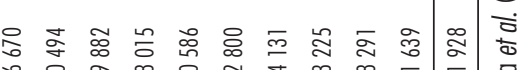
in ॠ

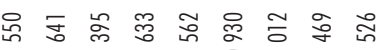

象

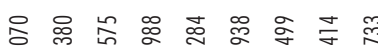

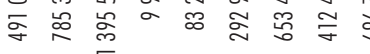

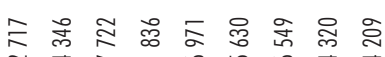
ฟ

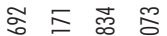

$\infty \infty \underset{\infty}{\infty}$

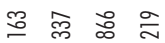
웡

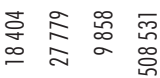

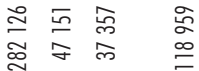

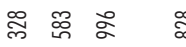
志出品

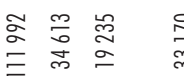

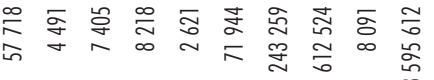

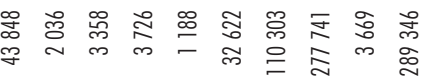

䒘

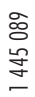

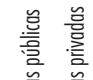

总

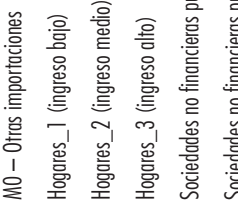

年

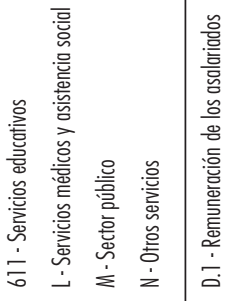

. 
De la MCs-México 2013 se desprenden agregados macroeconómicos que al compararse con la información de Cuentas Nacionales corroboran el nivel de certidumbre de la matriz (véase tabla 13).

Tabla 13. Comparativo de agregados macroeconómicos entre la MCS-
\begin{tabular}{lcc} 
México 2013 y el SCN de México 2013 (millones de pesos a precios de 2013) \\
\hline Variable & MCS-México 2013 & Cuentas Nacionales-INEGl \\
\hline PIB & 16288503 & 16277187 \\
Consumo intermedio & 8091685 & 8091685 \\
Exportaciones & 4915878 & 5068030 \\
Importaciones & 5248780 & 5251825 \\
Oferta agregada & 27642648 & 27642648 \\
Ahorro & 3436410 & 3661290 \\
FBKF & 3661290 & 3661290 \\
\hline
\end{tabular}

Nota: ${ }^{0}$ No se incluyen las importaciones intermedias.

Fuente: elaboración propia con base en MCS-México 2013 e INEGI (2018c).

En la MCs-México 2013 por el lado del gasto (columna 39 T-Ingreso) se obtuvo un valor total de MXN\$ 83712129 millones, similar al obtenido por el lado del gasto (renglón 39 T-Gasto); sin embargo, existe una discrepancia de MXN\$152 mil millones, equivalente al 0.18\% del valor total de los ingresos y gastos de la matriz, mismos que son registrados en la columna de UFOs. Lo anterior es resultado de que en algunos casos los valores de los renglones no tienen una coincidencia exacta con su respectiva columna.

Para solucionar la discrepancia entre el total de ingresos y gastos es necesario profundizar en al menos tres transacciones de cuentas que reportan inconsistencias de origen: las importaciones totales reportadas en la MIP respecto al valor de las importaciones en el SCI; el pago de remuneraciones del resto del mundo a los hogares (distinto al valor reportado por remesas); este valor se reporta en el SCI, pero no en la MIP; y las transferencias realizadas entre sectores interinstitucionales en la subcuenta D.759-Otras transferencias corrientes diversas; esta cuenta del SCI es la única que no cumple con el principio de partida doble (Total de cargos=Total de abonos). 


\section{ANÁLISIS DE LOS RESULTADOS}

Los resultados de la MCs-México 2013 (véase tabla 13) reflejan la situación de la estructura productiva y de los sectores institucionales de la económica mexicana. En la matriz se incluye además de la producción, la distribución del ingreso y el gasto de los sectores, con lo que se completa el puente de análisis que da lugar a una herramienta metodológica para el estudio del desarrollo económico desde una perspectiva interinstitucional de la estructura productiva mexicana.

Para mostrar la utilidad de la MCs-México 2013 se presenta un breve análisis contable de la economía mexicana. Cabe destacar que las actuales características de la estructura productiva y de distribución del ingreso son resultado de políticas neoliberales que, desde la década de 1980 del siglo xx, sesgaron la economía hacia el exterior promoviendo una fuerte dependencia de los mercados internacionales, de los insumos importados y de la inversión extranjera directa, provocando una salida del excedente económico a través de los déficits en balanza comercial, remesas de utilidades de las empresas extranjeras y fuga de capitales (Puyana, 2020; Romero, 2020; Blancas, 2015). Lo anterior se traduce en bajas tasas de crecimiento económico con alta concentración del ingreso y mayores niveles de pobreza y exclusión social de los sectores de población con menores niveles de ingreso y oportunidades sociales ${ }^{7}$ (Blancas y Aliphat, 2020).

En el cuadrante I de la MCs se observa que el consumo intermedio representa $29 \%$ de la oferta total, mientras que las importaciones constituyen 14\%; una relación de casi 2 a 1 entre los insumos locales e importados. Además, $48 \%$ del total de las importaciones corresponde a bienes eléctricos, electrónicos y de transporte donde el subsector G-Fabricación de bienes eléctricos, electrónicos y de transporte concentra $75 \%$ de la demanda de estos bienes importados.

La tabla 14 evidencia la vocación exportadora de los sectores primario y secundario, más del $25 \%$ de su demanda corresponde a exportaciones, algo característico de las llamadas economías globales (List, 1997), que a diferencia de las economías nacionales no tienen como objetivo el desarrollo de las fuerzas productivas nacionales. Dentro de una economía nacional, el objetivo es

7 Entre 1994 y 2013 la tasa de crecimiento anual del pIB fue de $2.4 \%$ y de las exportaciones del 6.4\%. En este mismo periodo, el Índice de Desarrollo Humano apenas pasó de 0.647 (1992) a 0.756 (2013); de acuerdo con datos del Coneval, para 2014, 46\% de la población se encontraba en situación de pobreza y $58 \%$ carecía de seguridad social. 
garantizar que la producción se destine a proveer el mercado interno y no las cadenas globales de producción. Por el lado de la producción, el problema se centra en las importaciones del sector secundario, ya que este sector en lugar de cumplir un papel como eje de integración entre el sector primario y terciario dentro de la economía nacional, se inserta como articulador en la economía global acosta del sistema de producción nacional (Romero y Aliphat, 2019; Vázquez, 2020).

Tabla 14. Composición de la demanda y oferta total por sector económico en 2013 (porcentaje respecto al total por sector de actividad económica)

\begin{tabular}{|c|c|c|c|c|c|c|c|}
\hline \multirow{3}{*}{$\begin{array}{l}\text { Sector } \\
\text { económico }\end{array}$} & \multicolumn{4}{|c|}{ Demanda total } & \multicolumn{3}{|c|}{ Oferta total } \\
\hline & \multicolumn{2}{|c|}{ Nacional } & \multirow[t]{2}{*}{ Exportaciones } & \multirow{2}{*}{$\begin{array}{c}\text { Demanda } \\
\text { total } \\
(\%)\end{array}$} & \multirow{2}{*}{$\begin{array}{c}\text { Producción } \\
\text { nacional }\end{array}$} & \multirow{2}{*}{$\begin{array}{c}\text { Extraniera } \\
\text { (importaciones) }\end{array}$} & \multirow{2}{*}{$\begin{array}{c}\text { Oferto } \\
\text { total } \\
(\%)\end{array}$} \\
\hline & Insumos & $\begin{array}{l}\text { Consumo } \\
\text { final }\end{array}$ & & & & & \\
\hline Sector primario & 59 & 15 & 27 & 100 & 94 & 6 & 100 \\
\hline Sector secundario & 26 & 44 & 29 & 100 & 74 & 26 & 100 \\
\hline Sector terciario & 28 & 67 & 5 & 100 & 96 & 4 & 100 \\
\hline
\end{tabular}

Fuente: elaboración propia con base en MCS-México 2013.

Desde la perspectiva de los sectores institucionales (véase tabla 15), el rubro de sectores productivos e importaciones intermedias (15A) muestra que $64 \%$ de las importaciones corresponde a bienes y servicios intermedios destinados al sector secundario. Bajo las condiciones de la MCs-México 2013 una mayor demanda del sector secundario podría incrementar las importaciones; así como una política económica enfocada a promover una mayor demanda de bienes secundarios se traduciría en saldos deficitarios de balanza comercial con pocos efectos sobre la economía nacional.

Por el lado de los hogares (véase tabla 15B), 11\% de las importaciones totales corresponde a bienes de consumo y se encuentra una relación directa entre el ingreso de los hogares y la demanda de bienes de consumo importado. Promover que los hogares reduzcan su propensión a importar fortalecería la economía nacional y haría que las transferencias gubernamentales, además de tener un efecto positivo en la distribución del ingreso y reducción de la 
Tabla 15. Destino de importaciones por sector productivo, tipo de hogar y tipo de bien para inversión en 2013 (porcentaje respecto al total de importaciones)

\begin{tabular}{|c|c|c|c|}
\hline Destino de las importaciones & Intermedio & Consumo & Inversión \\
\hline \multicolumn{4}{|l|}{ 15A Sectores productivos } \\
\hline Sector primario & 2.55 & & \\
\hline Sector secundario & 63.91 & & \\
\hline Sector terciario & 11.07 & & \\
\hline Subtotal & $77.53 \%$ & & \\
\hline \multicolumn{4}{|l|}{ 15B Hogares } \\
\hline Ingreso bajo & & 2.19 & \\
\hline Ingreso medio & & 4.40 & \\
\hline Ingreso alto & & 5.19 & \\
\hline Subtotal & & $11.78 \%$ & \\
\hline \multicolumn{4}{|l|}{ 15C Inversión por tipo de bien } \\
\hline MD - Industria alimentos y bebidas & & & 0.001 \\
\hline ME - Productos derivados del petróleo, química y plásticos & & & 0.14 \\
\hline MG - Bienes eléctricos, electrónicos y de transporte & & & 9.23 \\
\hline MO - Otras importaciones & & & 1.32 \\
\hline Subtotal & & & $10.69 \%$ \\
\hline Total de importaciones & & $100 \%$ & \\
\hline
\end{tabular}

Fuente: elaboración propia con base en MCS-México 2013.

pobreza, fortalecieran mediante una mayor demanda de los hogares la estructura productiva nacional y con ello habría un mayor crecimiento económico.

En la tabla $15 \mathrm{C}$ se observa que $10 \%$ de las importaciones totales corresponden a bienes de inversión, de las cuales los bienes eléctricos, electrónicos y de transporte son los más demandados en una relación 9 a 10. Se puede concluir que en México hay un mercado potencial para la producción de bienes de capital, equivalente a MXN\$ 464 mil millones valor superior al consumo nacional de bienes del sector primario, según datos de la MCs.

La manera en que se distribuye el valor agregado entre los sectores institucionales, como resultado de la estructura productiva, es un aspecto central que la MCs-México 2013 permite visualizar. La tabla 16 indica que 54\% del pago 
de remuneraciones y 39\% del Ево corresponde a los hogares de ingreso alto; mientras que $3.7 \%$ de las remuneraciones se destinan a los hogares de ingreso bajo. Lo que muestra que una estrategia de política económica centrada únicamente en el crecimiento económico resultará en una mayor concentración del ingreso con sus inevitables efectos en el crecimiento de la pobreza (Expósito et al., 2017).

Tabla 16. Distribución del valor agregado por sector institucional en 2013 (miles de millones de pesos a precios constantes de 2013)

\begin{tabular}{|c|c|c|c|c|}
\hline Tipo de hogar & Remuneraciones & $\%$ & $E B O$ & $\%$ \\
\hline Ingreso bajo & 511 & 11 & 74 & 0.6 \\
\hline Ingreso medio & 1572 & 34 & 291 & 2.6 \\
\hline Ingreso alto & 2470 & 54 & 3932 & 35.0 \\
\hline Subtotal hogares & 4554 & 100 & 4297 & 39.0 \\
\hline Tipo de sociedad & & & $E B O$ & $\%$ \\
\hline Sociedades no financieras públicas & & & 745 & 6.7 \\
\hline Sociedades no financieras privadas & & & 3028 & 27.4 \\
\hline \multirow[t]{2}{*}{ Sociedades financieras } & & & 375 & 3.4 \\
\hline & & Subtotal sociedades & 4148 & 38 \\
\hline Depreciación & & & 2567 & 23.4 \\
\hline Total de valor agregado & 4554 & 100 & 8445 & 100.0 \\
\hline
\end{tabular}

Fuente: elaboración propia con base en MCS-México 2013.

El valor agregado distribuido entre las sociedades, 27\% (correspondiente al Ево), se destina a las sociedades no financieras privadas de control nacional o extranjero, mientras que sólo $3.4 \%$ se dirige a las sociedades financieras y $6.8 \%$ a sociedades no financieras públicas; se concluye que las sociedades no financieras privadas lideran la concentración del ево (19\% del valor agregado total). Para reposición del capital (depreciación) se emplea 23\% del valor agregado total.

El ingreso total de los sectores institucionales se compone del pago de los factores productivos y por las transferencias interinstitucionales. Al desagregar el ingreso de sectores institucionales, los hogares de ingreso bajo reciben 17\% 
de sus ingresos por concepto de transferencias del gobierno y 7\% por concepto transferencias del resto del mundo (remesas) (véase tabla 17). Los ingresos generados por las sociedades financieras tienen una alta relación con el gobierno ( $11 \%$ de sus ingresos). Además, el resto del mundo se encuentra estrechamente relacionado con las sociedades no financieras, lo que significa que cerca del $9 \%$ de sus ingresos corresponden al pago de utilidades o transferencias hechas por sociedades financieras nacionales en manos de no residentes.

Tabla 17. Proporción de los ingresos obtenidos por sector institucional en 2013 (porcentaje del ingreso total por sector institucional)

\begin{tabular}{lcccccc}
\hline Sector institucional & $\begin{array}{c}\text { Ingreso por } \\
\text { factores }\end{array}$ & Hogares & Sociedades & Gobierno & $\begin{array}{c}\text { Resto del } \\
\text { mundo }\end{array}$ & $\begin{array}{c}\text { Ingreso } \\
\text { total (\%) }\end{array}$ \\
\hline Hogares (promedio) & 65 & 0.2 & 22 & 10 & 3 & 100 \\
Ingreso bajo & 39 & 0.5 & 37 & 17 & 7 & 100 \\
Ingreso medio & 57 & 0.4 & 27 & 12 & 4 & 100 \\
Ingreso alto & 73 & 0.1 & 18 & 8 & 1.1 & 100 \\
Sociedades (promedio) & 73 & 8.9 & 12 & 4 & 2 & 100 \\
Sociedades no financieras públicas & 96 & 0.5 & 2 & 1.0 & 0.07 & 100 \\
Sociedades no financieras privadas & 88 & 3.3 & 6 & 1.2 & 2 & 100 \\
Sociedades financieras & 26 & 26 & 34 & 11 & 3 & 100 \\
Gobierno & 13 & 18 & 29 & 40 & 0.03 & 100 \\
Resto del mundo & $89 *$ & 0.2 & 9 & 2 & NA & 100 \\
\hline
\end{tabular}

Notas: * El resto del mundo recibe ingresos por importaciones de la economía nacional, que se registran en la tabla de pago de factores; NA: No Aplica.

Fuente: elaboración propia con base en MCS-México 2013.

Analizar la forma en que los sectores institucionales gastan sus recursos es esencial para entender el flujo de dinero de la economía y permite formular estrategias de transferencias gubernamentales con mayor efecto en el desarrollo del mercado interno. La tabla 18 presenta el gasto por rubro de los sectores institucionales; los hogares destinan $4.7 \%$ de su ingreso al resto del mundo, principalmente por concepto de importación de bienes de consumo, siendo los hogares de ingreso alto los que mayor cantidad de recursos destinan al 
exterior (16\%), cifra incluso superior a la proporción de gasto destinada al gobierno (14\%). Los hogares de ingreso bajo destinan una mayor proporción de su ingreso al consumo, por lo que su gasto tiene un mayor efecto en el desarrollo del mercado interno. Las sociedades no financieras privadas destinan $10 \%$ de sus ingresos a transferencias del exterior; los datos sugieren una fuga estructural de capitales en la economía mexicana. El gasto del gobierno se concentra en consumo (33\%) y transferencias a hogares (22\%). Por último, el resto del mundo concentra $92 \%$ de sus ingresos en consumo (exportaciones de la economía nacional), $6 \%$ en transferencias a los hogares y solamente $2 \%$ en transferencias a sociedades, cifra que contrasta con los ingresos que obtiene de las sociedades.

Tabla 18. Gasto por sectores institucionales en 2013 (porcentaje del ingreso total de cada sector institucional)

\begin{tabular}{|c|c|c|c|c|c|c|c|c|c|c|}
\hline \multirow{2}{*}{$\begin{array}{l}\text { Sector } \\
\text { institucional }\end{array}$} & \multicolumn{4}{|c|}{ Hogares } & \multicolumn{3}{|c|}{ Sociedades } & \multirow[t]{2}{*}{ Total } & \multirow[t]{2}{*}{ Gob } & \multirow{2}{*}{$\begin{array}{c}\text { Resto } \\
\text { del } \\
\text { mundo }\end{array}$} \\
\hline & Bajo & Medio & Alto & Total & $\begin{array}{l}\text { No fin } \\
\text { públicas }\end{array}$ & $\begin{array}{l}\text { No fin } \\
\text { privadas }\end{array}$ & Financieras & & & \\
\hline Consumo & 84 & 80 & 75 & 79 & & & & & 33 & 92 \\
\hline $\begin{array}{l}\text { Impuestos } \\
\text { directos }\end{array}$ & 5.0 & 4.8 & 4.7 & 4.8 & & & & & NA & 0.0 \\
\hline Importaciones & 4.9 & 5.0 & 4.3 & 4.6 & & & & & NA & NA \\
\hline Transferencias & 6 & 10 & 16 & 12 & 100 & 100 & 100 & 100 & 67 & 8 \\
\hline Hogares & 0.1 & 0.2 & 0.3 & 0.25 & 2 & 65 & 43 & 52 & 23 & 6 \\
\hline Ingreso bajo & 0.03 & 0.05 & 0.07 & 0.06 & 0.3 & 12 & 8 & 9 & 4 & 2 \\
\hline $\begin{array}{l}\text { Ingreso } \\
\text { medio }\end{array}$ & 0.04 & 0.1 & 0.12 & 0.09 & 0.5 & 19 & 13 & 15 & 7 & 3 \\
\hline Ingreso alto & 0.05 & 0.1 & 0.14 & 0.10 & 0.8 & 34 & 23 & 27 & 12 & 2 \\
\hline Sociedades & 1.9 & 3.2 & 5.3 & 4.0 & 3.5 & 9 & 39 & 12 & 4 & 2 \\
\hline Gobierno & 3.6 & 6.2 & 10 & 7.6 & 92 & 16 & 9 & 28 & 38 & 0.03 \\
\hline $\begin{array}{l}\text { Resto del } \\
\text { mundo }\end{array}$ & 0.0 & 0.08 & 0.13 & 0.10 & 3 & 10 & 9 & 9 & 2 & NA \\
\hline Total & 100 & 100 & 100 & 100 & 100 & 100 & 100 & 100 & 100 & 100 \\
\hline
\end{tabular}

Nota: NA: No Aplica.

Fuente: elaboración propia con base en MCS-México 2013. 
Finalmente, en la tabla 19 se analiza la composición de la inversión (FBKF) de la economía, 66\% de la inversión se concentra en el sector secundario; sin embargo, $54 \%$ se dirige a construcción. Como se observa en la MCs, en México la inversión se traduce principalmente en edificios y no en maquinaria; $7.5 \%$ del gasto de inversión en el sector servicios se concentra en el sector I-Comercio de abarrotes, alimentos, bebidas, hielo y tabaco y sólo $0.2 \%$ se destina al sector K-Telecomunicaciones. Se gasta 70 veces más en FBKF para tiendas de bienes de consumo primario final que en Tecnologías de la Información y la Comunicación (TIC).

\section{Tabla 19. Destino de la inversión (FBKF) (miles de millones de pesos a precios de 2013)}

\begin{tabular}{lrc}
\hline Inversión & \multicolumn{1}{c}{ Valor } & $\%$ \\
\hline Sector primario & 215994 & 6.3 \\
Sector secundario & 2266968 & 66.0 \\
C-Construcción y servicios relacionados & 1879322 & 54.7 \\
D-Industria alimentos y bebidas & 2089 & 0.1 \\
E-Productos derivados del petróleo, química y plásticos & 1962 & 0.1 \\
F-Industrias minerales y no metálicas & 53971 & 1.6 \\
G-Fabricación de bienes eléctricos, electrónicos y de transporte & 302942 & 8.8 \\
H-Otras industrias & 26683 & 0.8 \\
Sector terciario & 399023 & 11.6 \\
I-Comercio de abarrotes, alimentos, bebidas, hielo y tabaco & 256911 & 7.5 \\
K-Telecomunicaciones & 7375 & 0.2 \\
Importaciones & 537763 & 15.6 \\
MD-Industria alimentos y bebidas & 683 & 0.0 \\
ME-Productos derivados del petróleo, química y plásticos & 7202 & 0.2 \\
MG-Fabricación de bienes eléctricos, electrónicos y de transporte & 464062 & 13.5 \\
MO-Otras importaciones & 66431 & 1.9 \\
Impuestos indirectos & 16662 & 0.5 \\
\hline Total & 310 & 100.0 \\
\hline
\end{tabular}

Fuente: elaboración propia con base en MCS-México 2013. 
Sobre importaciones de bienes de inversión, la economía mexicana se abastece de bienes de capital principalmente del extranjero, el porcentaje de importaciones relacionadas con bienes eléctricos, electrónicos y de transporte equivale al gasto total por FBKF del sector secundario (con excepción del gasto en construcción). Con los datos de la tabla 19 se concluye que por cada 100 pesos destinados a la inversión en México en 2013, 54 se emplearon en actividades de construcción, 15 en importar bienes de capital y solamente 11 en maquinaria y equipo nacional.

\section{CONCLUSIONES}

El análisis contable que se deriva de la elaboración de la MCs-México 2013 permite profundizar en las relaciones intra e interinstitucionales de una economía sistémica, encontrándose una estructura productiva altamente vinculada al exterior y en la que persisten severos problemas de distribución del ingreso. La información que ofrece la MCs sugiere que las transferencias del gobierno a los hogares representan un incremento en las importaciones de bienes intermedios, lo que es un elemento trascendental en el estudio de la demanda efectiva y el crecimiento económico.

En materia de desarrollo económico, el análisis contable de la MCs-México 2013 evidencia que los hogares de bajos ingresos tienen una alta dependencia de las transferencias de gobierno y de recursos provenientes fuera de la economía (remesas); es necesario, pues, que esta categoría de hogares incremente sus ingresos obtenidos de la esfera productiva, ya sea mediante salarios más altos о en la medida de lo posible por вво. Una propuesta que podría derivarse de este análisis es consolidar cooperativas que distribuyan entre los trabajadores al Ево generado.

Como resultado del análisis contable, el presente documento permitirá realizar futuros estudios del desarrollo económico que consideren el uso de la MCs-México 2013 y profundicen en el análisis interinstitucional a través de multiplicadores contables y/o modelos de equilibrio general computable. 


\section{BIBLIOGRAFÍA}

Banegas, R. y Blancas, A. (2019). The foreign saving moderating effect on public spending in Mexico. Revista Nicolaita de Estudios Económicos, 14(1). https://doi.org/10.33110/rnee.v14i1.285

Blancas, A. (2006). Interinstitutional linkage analysis: a social accounting matrix multiplier approach for the Mexican economy. Economic Systems Research, 18(1). https://doi.org/10.1080/09535310500440548 (2010). La fragilidad financiera en México. UNAM.

(2015). Fuga de capitales en México: análisis y propuesta de medición. Problemas del Desarrollo. Revista Latinoamericana de Economía, 46(181). https://doi.org/10.1016/j.rpd.2015.01.001

Blancas, A. y Aliphat, R. (2020). Empleo decente digno y salario justo en el crecimiento de la productividad laboral en México. En A. Sánchez, I. Nava y N. Cruz (coords.), Bienestar y politicas públicas (pp. 281-310). UNAMIIEC.

Breisinger, C., Thomas, M. y Thurlow, J. (2009). Social accounting matrices and multiplier analysis: An introduction with exercises, vol. 5. IFPRI.

Bustos, A. y Leyva, G. (2017). Towards a more realistic estimate of the income distribution in Mexico. Latin American Policy, 8(1). https://doi. org/10.1111/lamp.12114

Cardona, G., Cardenete, M. y Martínez, C. (2018). Estructura económica mexicana: sectores claves, estratégicos, impulsores e independientes 2012. Revista de Economia, 35(90). https://doi.org/10.33937/reveco.2018.90

Casares, E., García, M. y Sobarzo, H. (2017). Las matrices de contabilidad social como base de datos y soporte de modelos multisectoriales. EconoQuantum, 14(1). https://doi.org/10.18381/eq.v14i1.6544

Chapa, C., Mosqueda, M. y Rangel, E. (2019). Matrices de contabilidad social para las regiones de México (documentos de trabajo 2019-20). Banco de México. https://www.banxico.org.mx/viewers2/JSP/docsInvestigacionAnio_es.jsp?static=y

Cortés, F. (2018). Desigualdad en el ingreso en México, 1963 a 2014. En A. Puyana y M. Puchet (coords.), América Latina en la larga historia de la desigualdad. Una revisión de causas, efectos y politicas (pp.119-146). FLACso.

Expósito, A., Fernández, J. y Velasco, F. (2017). Crecimiento económico, pobreza y desigualdad: un análisis de eficiencia para América Latina en el siglo xxi. Revista de Economía Mundial, 47(1). http://dx.doi.org/10.33776/ rem.v0i47.3869 
Instituto Nacional de Estadística y Geografía (INEgi) (2013a). Sistema de Clasificación Industrial de América del Norte, México (SCIAN 2013). INEGI. http://www.inegi.org.mx

(2013b). Sistema de cuentas institucionales 2013. INEGI. http://www. inegi.org. $\mathrm{mx}$

(2014). Encuesta Nacional de Ingresos y Gastos de los Hogares 2014 (ENIGH) [sitio de internet]. México, INEGI. http://www.inegi.org.mx (2018a). Matriz Insumo-Producto 2013. INEGI. http://www.inegi.org. $\mathrm{mx}$

(2018b). Sistema de Cuentas Nacionales de México: fuentes y metodologias: año base 2013. INEGI. http://www.inegi.org.mx

(2018c). Sistema de Cuentas Nacionales de México 2013. INEGI. http://www.inegi.org.mx

Leontief, W. (1941). The structure of American economy, 1919-1939. Oxford.

Leyva, G. (2004). El ajuste del ingreso de la ENIGH con la contabilidad nacional y la medición de la pobreza en México. (Serie documentos de investigación 19). SEDESOL. https://portalsocial.guanajuato.gob.mx/sites/ default/files/documentos/2004_SEDESOL_El\%20ajuste\%20del\%20 ingreso $\% 20 \mathrm{de} \% 20 \mathrm{la} \% 20$ Enigh.PDF

List, F. (1997). Sistema nacional de economía política: con el anexo esbozos de economía politica americana. FCE. (Original publicado en 1841).

Nava, I. y Brown, F. (2018). Determinantes del ahorro de los hogares en México: un análisis de regresión cuantílica. Economía: teoría y práctica, 49. https://doi.org/10.24275/ETYPUAM/NE/492018/Nava

Núñez, G. y Romero, J. (2020). Nacionalismo y desarrollo: una alternativa para México. Revista CEPAL. 131(1). https://www.cepal.org/es/publica ciones/45961-nacionalismo-desarrollo-alternativa-mexico

Organización de las Naciones Unidas (onu) (1993). Sistema de Cuentas Nacionales 1993. ONU.

(2016). Sistema de Cuentas Nacionales 2008. ONU.

Organización Internacional del Trabajo (огт) (2019). Manual de uso de modelos de equilibrio general computable compactos, (Strengthen working paper), oIT. https://www.ilo.org/wcmsp5/groups/public/---ed_emp/documents/publication/wcms_741481.pdf

Puyana, A. (2020). Del Tratado de Libre Comercio de América del Norte al Acuerdo México-Estados Unidos-Canadá. ¿Nuevo capítulo de la integración México-Estados Unidos? El Trimestre Económico, 87(347). https:// doi.org/10.20430/ete.v87i347.1086 
Quesnay, F. (1894). Tableau économique. MacMillan\&Company. (Original publicado en 1758).

Robinson, S., Cattaneo, A. y El-Said, M. (2001). Updating and estimating a social accounting matrix using cross entropy methods. Economic Systems Research, 13(1). https://doi.org/10.1080/09535310120026247

Romero, J. (2020). La herencia del experimento neoliberal. El Trimestre Económico, 87(345). https://doi.org/10.20430/ete.v87i345.1029

Romero, J. y Aliphat, R. (2019). Import demand for intermediate goods in Mexico: 1993-2018. Atlantic Review of Economics, 3(3). http://www.aroec. org/ojs/index.php/ARoEc/article/view/93

Stone, R. (1956). Input-output and the social accounts. University of Cambridge.

Vázquez, R. (2020). Efectos de las reformas del Consenso de Washington sobre la estructura industrial: los casos de México e India. América Latina en la Historia Económica, 27(3). https://doi.org/10.18232/alhe.1069

Villatoro, P. (2015). Ajuste de los ingresos de las encuestas a las Cuentas Nacionales: una revisión de la literatura. (Serie estudios estadísticos 91). CEPAL. https://repositorio.cepal.org/handle/11362/37957 
